\title{
Potencial antifúngico de quitosanases extracelulares de Fusarium solani FA14 contra os fitopatógenos Aspergillus niger, Colletotrichum gloeosporioides e Lasiodiplodia theobromae
}

Antifungal potential of extracellular chitosanases from Fusarium solani FA14 against plant pathogens Aspergillus niger, Colletotrichum gloeosporioides and Lasiodiplodia theobromae

\author{
S. A. Bezerra Neto ${ }^{1}$; L. N. F. da Costa ${ }^{2}$; E. A. Magalhães ${ }^{3}$, F. L. A. Batista \\ L. F. W. G. Moura'; M. G. A. Franca 3 ; C. F. de Paiva 3 ; D. R. de Lima3; \\ M. V. de Oliveira ${ }^{3}$; M. I. F. Guedes², F. C. O. Freire ${ }^{4}$, F. E. A. Magalhães ${ }^{3 *}$

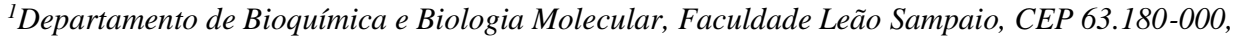 \\ Juazeiro do Norte, Ceará, Brasil. \\ ${ }^{2}$ Laboratório de Biotecnologia e Biologia Molecular, Universidade Estadual do Ceará, CEP 60740-000, Fortaleza, \\ Ceará, Brasil; \\ ${ }^{3}$ Laboratório de Bioprospecção de Produtos Naturais e Biotecnologia, CEP 63660-000, Tauá, Ceará, Brasil. \\ ${ }^{4}$ Laboratório de Fitopatologia, Embrapa Agroindústria Tropical, CEP 60511-110, Fortaleza, Ceará, Brasil; \\ *fernanimagalhaes@yahoo.com.br \\ (Recebido em 27 de fevereiro de 2016; aceito em 7 de novembro de 2016)
}

\begin{abstract}
O trabalho reporta o potencial antifúngico de quitosanases extracelulares do fungo Fusarium solani FA14 contra os fitopatógenos Aspergillus niger, Colletotrichum gloeosporioides e Lasiodiplodia theobromae. Inicialmente, a cepa foi submetida a ensaio de atividade quitosanase (AQ) e se mostrou ativa, com valor de AQ igual a 1,1 significantemente igual $(\mathrm{p}<0,05)$ ao do controle positivo, Penicillium sp. Posteriormente a cepa foi empregada como fonte de quitosanases extracelulares para avaliar o percentual de inibição do crescimento (PIC) dos fungos Aspergillus niger, Colletotrichum gloeosporioides, Lasiodiplodia theobromae. Como resultado, o extrato enzimático de $F$. solani FA14 se mostrou ativo contra todos os fungos desafiados, com valores de PIC variando de 21 a $64 \%$, significantemente maiores $(\mathrm{p}<0,05)$ do que os dos extratos do Penicillium sp. O extrato enzimático do $F$. solani FA14 apresentou atividade antifúngica mais expressiva contra o fitopatógeno Lasiodiplodia theobromae, com valor de PIC igual a $64 \%$, significantemente maior $(\mathrm{p}<0,05)$ do que os dos extratos do Penicillium sp. (PIC $=50 \%$ ). Palavras-chave: Fungo anemófilo, Quitosanases extracelulares, Atividade antifúngica.
\end{abstract}

The work reports the antifungal potential of extracellular chitosanases from Fusarium solani FA14 against plant pathogens Aspergillus niger, Colletotrichum gloeosporioides and Lasiodiplodia theobromae. Initially, the strain was subjected to activity assay chitosanase (AC) and proved to be active with $\mathrm{AC}$ value equal to 1.1 significantly equal $(\mathrm{p}<0,05)$ to the positive control, Penicillium sp. Subsequently the strain was used as a source of extracellular chitosanases to assess the percentage of growth inhibition (PGI) of L. theobromae, A. niger, and C. gloeosporioides. As a result, the enzyme extract were active against all fungi challenged with PGI values ranging from 21 to $64 \%$, significantly higher $(\mathrm{p}<0,05)$ than those of extracts from Penicillium sp. The enzyme extract of $F$. solani FA14 showed significant antifungal activity against the plant pathogen Lasiodiplodia theobromae, with PGI equal to $64 \%$, significantly higher $(\mathrm{p}<0,05)$ than those of extracts from Penicillium sp. (PIC $=50 \%$ ).

Keywords: Anemophilou fungi, Extracellular chitosanases, Antifungal activity. 


\section{INTRODUÇÃO}

$\mathrm{O}$ vasto número e variedade de produtos naturais isolados de microrganismos para o tratamento de infecções bacterianas e fúngicas contribuíram grandemente para a melhoria da saúde humana durante o último século. Porém, só um número limitado de agentes antifúngicos como os polienos e azóis estão atualmente disponíveis para o tratamento de infecções fúngicas. Além disso, o surgimento de infecções fúngicas sistêmicas aumentou significativamente durante a última década. Por isto, o desenvolvimento de novos agentes antimicrobianos, preferencialmente com novos mecanismos de ação, é uma necessidade [1].

Pesquisas enfocando a bioprospecção de atividade antimicrobiana reportam microrganismos como grandes produtores de novos agentes antibióticos [1], bem como de enzimas capazes de inibir o crescimento celular de fungos [2]. Podemos citar como exemplo as quitosanases, as quais são enzimas hidrolíticas que degradam a quitosana existente nas paredes celulares de um grupo limitado de microrganismos do gênero Rhizopus, Absidia e Fusarium, impedindo assim suas proliferações [3].

Do ponto de vista biotecnológico, as quitosanases de microrganismos têm aplicação na agricultura sendo empregadas como agentes de biocontrole de fungos fitopatógenos, bem como desempenham importante papel na regeneração de carbono e nitrogênio na natureza. Elas também têm merecido destaque na medicina, na indústria de alimentos através do processamento de biomateriais quitinolíticos e quitooligossacarídeos bifuncionais, bem como na química orgânica na preparação de estruturas de oligossacarídeos sintéticos [4-7].

Diante desse contexto, esse trabalho teve como objetivo investigar o potencial antifúngico de quitosanases extracelulares do fungo anemófilo Fusarium solani FA14 contra os fitopatógenos Aspergillus niger, Colletotrichum gloeosporioides e Lasiodiplodia theobromae.

\section{MATERIAL E MÉTODOS}

\section{Fungo utilizado}

A estirpe Fusarium solani FA14 utilizada nesse trabalho foi isolada do ar (ambiente climatizado, $18 \pm 2^{\circ} \mathrm{C}$ ), no Laboratório de Bioquímica Humana ( $3^{\circ} 47^{\prime} 50^{\prime}$ ' S, $38^{\circ} 33^{\prime} 24^{\prime}$ ' W), da Universidade Estadual do Ceará, Fortaleza, Ceará [8]. Os fungos fitopatogênicos Aspergillus niger, Colletotrichum gloeosporioides e Lasiodiplodia theobromae foram cepas cedidas do Laboratório de Fitopatologia da Embrapa Agroindústria Tropical.

\section{Preparo de meio de cultura Agar-Quitosana}

O meio de cultura Agar-Quitosana foi preparado de acordo com metodologias propostas por Barreto et al. [9], com adaptações. A quitosana foi doada, gentilmente, pelo Parque de Desenvolvimento Tecnológico (PADETEC), da Universidade Federal do Ceará. Inicialmente foi preparada uma solução de $1,00 \mathrm{~g}$ de quitosana (Grau de Desacetilação, GD, 75\%, ) dissolvida em $200 \mathrm{~mL}$ de ácido acético (1\%) que ficou sob agitação por $2 \mathrm{~h}$ à temperatura ambiente. Essa solução de quitosana foi posteriormente misturada com $300 \mathrm{~mL}$ de meio sais minerais [1]. A solução resultante foi levada ao peagâmetro para ajuste do $\mathrm{pH}$ da solução ácida até 6,0 , com solução de hidróxido de sódio $(\mathrm{NaOH}) 1 \mathrm{M}$. Separadamente, foram preparados 500 $\mathrm{mL}$ de uma solução de agar $(4 \%)$. As soluções de quitosana com sais minerais e de agar foram esterilizadas em autoclave a $110{ }^{\circ} \mathrm{C}$ por 10 minutos. Após serem retiradas da autoclave, as soluções foram resfriadas naturalmente, em capela de fluxo laminar, até atingirem $50{ }^{\circ} \mathrm{C}$, quando então foram misturadas, perfazendo total de $1000 \mathrm{~mL}$. Um total de $20 \mathrm{~mL}$ de meio Agar-Quitosana foi distribuído em cada placa de Petri de vidro $(80 \times 15 \mathrm{~cm})$, estéril, e acondicionada em geladeira $\left(5^{\circ} \mathrm{C}\right)$ até utilização.

\section{Screening preliminar de atividade quitosanase}

O screening preliminar de atividade quitosanase do $F$. solani FA14 foi realizado com base em metodologias de Shimosaka et al. [3], com adaptações. Os ensaios foram realizados por meio do método de difusão em gel, em placas de Petri de vidro $(80 \times 15 \mathrm{~cm})$. Como adaptações do método, inicialmente, as cepas fúngicas foram repicadas em meios de cultura batata-dextrose-agar sintético (BDA), durante sete dias, à temperatura ambiente $\left(30 \pm 2^{\circ} \mathrm{C}\right)$. 
Posteriormente, um disco de $5 \mathrm{~mm}$ da cepa pura de $F$. solani FA14 foi repicada pontualmente nos centros de placas de Petri, contendo meio de cultura Agar-Quitosana. O crescimento vegetativo foi realizado à temperatura ambiente $\left(30 \pm 2^{\circ} \mathrm{C}\right)$, por um período de quatro dias. A atividade quitosanase foi caracterizada através de formação de halo incolor ao redor das colônias, indicativa da hidrólise da quitosana em oligassacarídeos pela ação da enzima. Os ensaios foram realizados em triplicata e o fungo Penicillium sp. foi utilizado como controle positivo [10]. Os resultados foram expressos de acordo com a fórmula $A Q=H / h$, onde $A Q$ é a atividade quitosanase, $H$ corresponde à média dos halos incolores formados ao redor das colônias (em milímetros) e $h$ à média dos halos das colônias (em milímetros), ambos medidos com auxílio de um paquímetro universal.

\section{Produção de quitosanases extracelulares}

A produção de quitosanase extracelulares do fungo $F$. solani foi realizada conforme Zhang et al. [11] e Zhou et al. [12], com adaptações. A cepa fúngica foi inicialmente repicada em placa de Petri, contendo meio de cultura Agar-Quitosana, por um período de sete dias, à temperatura ambiente $\left(30 \pm 2^{\circ} \mathrm{C}\right)$. Após esse período, 1 disco de $5 \mathrm{~mm}$ de diâmetro de cultura pura do fungo foi inoculado em frascos ampolas $(20 \mathrm{~mL})$, contendo $10 \mathrm{~mL}$ de meio de cultura líquido quitosana, preparado como descrito anteriormente, sem agar. $\mathrm{O}$ crescimento vegetativo foi realizado por sete dias, sem agitação a temperatura ambiente $\left(30 \pm 2^{\circ} \mathrm{C}\right)$. Posteriormente, sob condições assépticas, as biomassas foram separadas dos meios extracelulares por filtração simples, utilizando-se papel de filtro Whatman \#1, e descartadas. Os meios extracelulares obtidos foram esterilizados por centrifugação a $9.000 \mathrm{~g}$ durante 30 minutos. Os pellets foram descartados e os sobrenadantes, denominados de extratos enzimáticos quitosanases, foram acondicionado em eppendorfs estéreis e estocados em geladeira $\left(5^{\circ} \mathrm{C}\right)$. $\mathrm{O}$ experimento foi realizado em triplicata e o fungo Penicillium sp. foi utilizado como controle positivo [10]. Como controle negativo, foi utilizado o próprio meio de cultura líquido quitosana, sem a presença de cepas fúngicas.

\section{Determinação de proteínas dos meios extracelulares}

As proteínas dos meios extracelulares foram determinadas baseando-se em metodologia proposta por Bradford [13], utilizando-se albumina sérica bovina como padrão. As leituras das absorbâncias foram medidas em espectrofotômetro, a $595 \mathrm{~nm}$.

\section{Bioprospecção de atividade antifúngica de quitosanases extracelulares}

A bioprospecção de atividade antifúngica de quitosanases extracelulares da cepa ativa foi realizada de acordo com metodologias propostas por Chang, Chen e Jaó [14] e Magalhães [1], com adaptações. Esse ensaio foi realizado através do teste do desafio in vitro, em placas de Petri $(80 \times 15 \mathrm{~cm})$, contendo meio de cultura BDA, e aplicando-se a técnica de perfuração feita com pipetas de Pasteur, obtendo poços de $5 \mathrm{~mm}$ de diâmetro, há $2 \mathrm{~cm}$ de cada extremidade das placas. Nas extremidades à esquerda das placas foram aplicados $50 \mu \mathrm{L}$ de amostra (extratos dos meios extracelulares) e, em posição oposta, foram semeados um disco de $5 \mathrm{~mm}$ de diâmetro da cultura pura dos fitopatógenos a serem desafiados (Lasiodiplodia theobromae, Aspergillus niger e Colletotrichum gloesporioides). O crescimento vegetativo foi realizado até o $7^{\circ}$ dia, a temperatura ambiente $\left(30 \pm 2^{\circ} \mathrm{C}\right)$. Os ensaios foram realizados em triplicata, tanto para o desafio como para os controles dos fungos (testemunhos), repicados em meio BDA separadamente. $\mathrm{O}$ meio líquido quitosana sem crescimento fúngico e o meio extracelular do fungo Pencicillium sp., cultivado em meio líquido Quitosana nas mesmas condições do experimento, foram utilizados como controles negativo e positivo, respectivamente. A atividade antifúngica foi caracterizada medindo-se a taxa de crescimento radial das colônias dos fitopatógenos (em milímetros, com auxílio de um paquímetro universal), até o encontro dos poços contendo as amostras, com surgimento de zonas de inibição do crescimento celular. Os resultados foram apresentados através da média das percentagens de inibição do crescimento micelial dos fitopatógenos desafiados (PIC), conforme a equação: PIC $=\{[($ CMPT-CMPD $) / C M P T] x$ $100 \%$ \}, onde CMPT significa crescimento micelial do patógeno testemunho e CMPD significa crescimento micelial do patógeno no desafio. Os extratos foram classificados em: sem atividade antifúngica, SAA (PIC=0\%); com pouca atividade antifúngica, PAA $(0 \%<$ PIC < 50\%), com moderada atividade antifúngica, MAA $(50 \% \leq \mathrm{PIC} \leq 75 \%)$ e com elevada atividade antifúngica, EAA (PIC > 75\%), para cada fitopatógeno desafiado. 


\section{Análise estatística}

Os resultados de todos os experimentos foram analisados segundo suas médias e respectivos desvios-padrão, bem como submetidos à análise de variância (ANOVA) no programa GraphPadPrism (versão 5.0). Diferenças significativas ( $\mathrm{p}<0,05)$ entre as médias foram determinadas pelo teste de comparações múltiplas de Tukey [1].

\section{RESULTADOS E DISCUSSÃO}

$\mathrm{Na}$ busca por quitosanases extracelulares, diversos estudos vêm sendo reportados através da bioprospecção de atividade quitosanases de fungos isolados dos mais variados ambientes $[5,6]$. Nesse trabalho adotamos o método qualitativo empregando a quitosana (Grau de Desacetilação, GD, 75\%) como fonte de carbono para detectarmos a expressão de quitosanases extracelulares do fungo anemófilo $F$. solani FA14. Como resultado desse nosso screening preliminar, o $F$. solani FA14 se mostrou ativo, apresentando atividade quitosanase (AQ) igual a 1,1 em quatro dias de cultivo, significantemente igual $(\mathrm{p}<0,05)$ ao do controle positivo, Penicillium sp. (Figura 1).

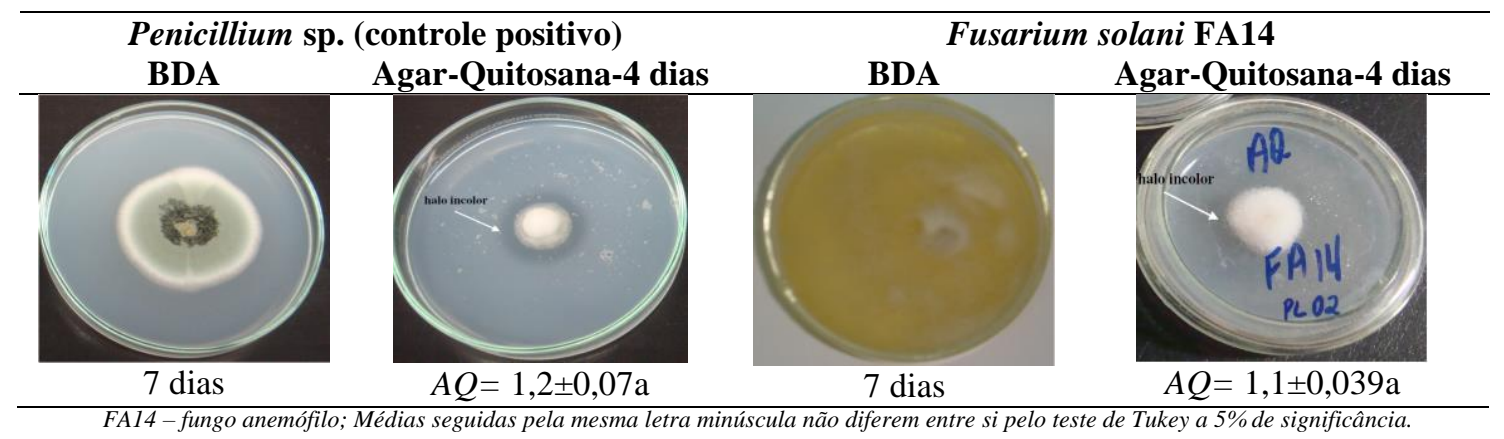

Figura 1: Screening preliminar de atividade quitosanase (AQ) de Fusarium solani FA14.

Resultados semelhantes foram encontrados por Shimosaka et al. [3], quando foram realizados screenings de atividade quitosanase de vários isolados fitopatogênicos do gênero Fusarium, utilizando o mesmo método. Como resultado, 22 isolados de Fusarium solani apresentaram atividade quitosanase positiva, tendo em vista a formação de halo incolor ao redor das colônias, característico da hidrólise da quitosana em oligossacarídeos.

A atividade antifúngica do extrato quitosanases extracelulares do Fusarium solani FA14 encontram-se representados na Tabela 1.

Tabela 1: Atividade antifúngica do extrato quitosanases extracelulares de Fusarium solani FA14.

\begin{tabular}{|c|c|c|c|c|c|c|c|}
\hline \multirow{2}{*}{$\begin{array}{c}\text { Extratos } \\
\text { Quitosanases }\end{array}$} & \multirow{2}{*}{$\begin{array}{c}\text { Proteína } \\
\text { total } \\
(\mathrm{mg} / \mathrm{mL})\end{array}$} & \multicolumn{2}{|c|}{ L. theobromae } & \multicolumn{2}{|c|}{ A. niger } & \multicolumn{2}{|c|}{ C. gloesporioides } \\
\hline & & PIC & $\mathbf{A A}$ & PIC & $\mathbf{A A}$ & PIC & $\overline{\mathbf{A A}}$ \\
\hline MLQ & $0,0 \pm 0,0 \mathrm{~A}$ & $0,0 \pm 0,0 \mathrm{~A}$ & SAA & $0,0 \pm 0,0 \mathrm{~A}$ & SAA & $0,0 \pm 0,0 \mathrm{~A}$ & SAA \\
\hline Penicillium sp. & $0,24 \pm 0,025 \mathrm{~B}$ & $50 \pm 0,0 \mathrm{aB}$ & MAA & $57 \pm 4,8 \mathrm{aB}$ & MAA & $24 \pm 4,7 \mathrm{bB}$ & PAA \\
\hline F. solani FA14 & $0,25 \pm 0,078 \mathrm{~B}$ & $64 \pm 3,9 \mathrm{aC}$ & MAA & $21 \pm 3,6 b C$ & PAA & $21 \pm 0,0 \mathrm{bB}$ & PAA \\
\hline
\end{tabular}


O extrato enzimático do fungo anemófilo $F$. solani FA14 se mostrou ativo contra todos os fungos desafiados, apresentando de pouca a moderada atividade antifúngica, com valores de PIC variando de 21 a $64 \%$, significantemente maiores $(\mathrm{p}<0,05)$ do que os dos extratos enzimáticos do controle positivo, Penicillium sp. $(24<\mathrm{PIC} \leq 57 \%)$.

Nestes experimentos, os extratos enzimáticos de $F$. solani FA14 apresentaram pouca atividade antifúngica contra os fungos A. niger e $C$. gloesporioides, com valores de PIC iguais a $21 \%$, significantemente semelhantes $(\mathrm{p}<0,05)$ entre si e entre os extratos enzimáticos do Penicillium sp. contra o C. gloesporioides. Já o extrato enzimático do Penicillium sp., apresentou moderada atividade antifúngica contra $A$. niger, com valor PIC igual a $57 \%$, significantemente semelhantes $(\mathrm{p}<0,05)$ contra o fitopatógeno L. theobromae.

O extrato enzimático quitosanases extracelulares de $F$. solani FA14 apresentou atividade antifúngica mais expressiva contra o fitopatógeno $L$. theobromae, com valor de PIC igual a $64 \%$, significantemente maior $(\mathrm{p}<0,05)$ do que o do extrato enzimático do controle positivo, Penicillium sp. $(\mathrm{PIC}=50 \%)($ Tabela 1 , Figura 2$)$.
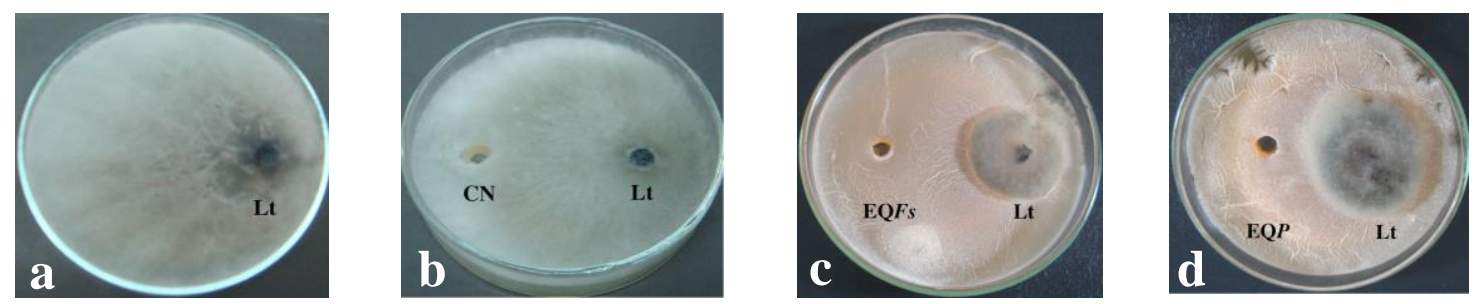

Figura 2: Atividade antifúngica de extrato enzimático quitosanases extracelulares de F. solani FA14: a) Lasiodiplodia theobromae no testemunho; b) $\mathrm{CN}$ - controle negativo (extrato do meio líquido quitosana) no desafio contra Lasiodiplodia theobromae; c) EQFs-extrato quitosanase do Fusarium solani FA14 no desafio contra Lasiodiplodia theobromae; d) EQP- extrato quitosanase do Penicillium sp. (fungo controle positivo) no desafio contra Lasiodiplodia theobromae.

De acordo com Shimosaka et al. [3], a inibição do crescimento celular dos fitopatógenos desafiados pode ser atribuída a presença de enzimas quitosanases nos meios extracelulares, em concentrações adequadas, capazes de degradarem as moléculas de quitosana presentes nas paredes celulares dos microrganismos, inibindo a proliferação dos mesmos. Assim, justifica-se que o extrato quitosanases extracelulares do $F$. solani FA14, que apresentou concentração de proteínas total igual a $0,25 \mathrm{mg} / \mathrm{mL}$, significantemente semelhante $(\mathrm{p}<0,05)$ ao extrato do fungo controle (Tabela 1), apresentou consideráveis inibições do crescimento celular dos patógenos desafiados, quando comparados com os extratos do fungo controle (Figura 2).

Os resultados apresentados nesse trabalho são relevantes, visto que não existe investigação prévia sobre screening preliminar de atividade quitosanase de estirpes Fusarium solani isolados do ar em ambientes climatizados, corroborando com a importância desta estirpe como fonte promissora de enzimas quitosanases extracelulares e com potencial antifúngico. 


\section{CONCLUSÃO}

O extrato quitosanase do $F$. solani FA14 apresenta atividade antifúngica expressiva contra o fitopatógeno $L$. theobromae, sendo assim importante para futuros estudos visando uma melhor caracterização das quitosanases extracelulares deste extrato e seus respectivos mecanismos de ação, para uso biotecnológico.

\section{AGRADECIMENTOS}

A Faculdade Leão Sampaio, Universidade Estadual do Ceará, à Embrapa Agroindústria Tropical, BNB, CNPq e FUNCAP pelo aporte de recursos financeiros. A Pesquisadora Dra. Técia Vieira de Carvalho (Parque de Desenvolvimento Tecnlógico-PADETEC-UFC) pela Quitosana fornecida.

\section{REFERÊNCIAS BIBLIOGRÁFICAS}

1. Magalhães FEA. "Potencial biotecnológico de fungos isolados do molusco Pugilina morio." 2011. 152f. Tese: Doutorado em Biotecnologia. Universidade Estadual do Ceará-UECE, Fortaleza, Ceará, 2011.

2. Rodrígues-Marin A., Acosta R, Liddell S, Núnez F, Benito MJ, Asensio MA. "Characterization of the novel antifungal chitosanase $\mathrm{PgChP}$ and the encoding gene from Penicillium chrysogenum." Appl. Microbiol. Biotechnol. 2010, 88:519-528.

3. Shimosaka M, Nogawa M, Ohno Y, Okzaki M. "Chitosanase from the plant pathogenic fungus, Fusarium solani f. sp. phaeseoli-Purification and some properties." Biosci. Biotech. Biochem. 1993, 57:231-235.

4. Somashekar D, Joseph R. "Chitosanases- Properties and Applications: A Review." Bioresource Technology. 1996, 55:35-45.

5. Kittur FS, Kumar A BV, Gowda LG, Thanaranathan RN. "Chitosanolysis by a pectinase isozyme of Aspergillus niger-A non-specific activity." Carbohydrate Polymers. 2003, 53:191-196, 2003.

6. Jung WJ, Kuk JH, Kim KY, Jung, KC, Park RD. "Purification and characterization of exo-Dglucosaminidase from Aspergillus fumigatus S-26." Protein Expression and Purification. 2006, 45:125-131.

7. van Bueren AL, Ghinet M G, Gregg K, Fleury A, Brzezinski R, Boraston AB. "The Structural Basis of

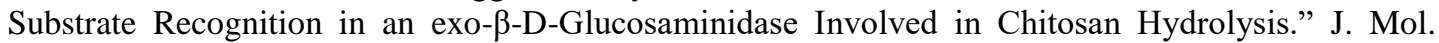
Biol. 2009, 385:131-139.

8. Brasilino ALS, Martins JM, Nobre GD, da COSTA LNF, Guedes MIFG, de Almeida LM, Magalhães FEA. "Bioprospecção dos fungos anemófilos Phaecilomyces sp, Trichoderma sp, Fusarium solani e Aspergillus terreus como um recurso de novas enzimas Álcool Desidrogenases (ADHs)." In: XV Semana Universitária da UECE, 2010. Anais...XV Semana Universitária da UECE, 2010. Disponível em <http://www.uece.br/semanauniversitaria $>$.

9. Barreto RVG, Hissa DC, Paes FA, Grangeito TB, Nascimento RF, Renelo LM, Craveiro AA, Melo VMM. "New approach for petroleum hydrocarbon degradation using bacterial spores entrapped in chitosan beads." Bioresource Technology. 2010, 101:2121-2125.

10. Cheng CY, Chang CH, Wu YJ, LI YK. "Exploration of Glycosyl Hydrolase Family 75, a Chitosanase from Aspergillus fumigatus.” The Journal of Biological Chemistry. 2006, 281:3137-3144.

11.Zhang XY, DAI AL, Zhang XK, Kuroiwa K, Kodaira R, Shimosada M. "Purification and characterization of chitosanase and exo-b-D-glucosaminidase from a koji mold. Aspergillus oryzae IAM2660." Bioscience Biotechnology and Biochemistry. 2000, 64:1896-1902.

12. Zhou W, Yuan H, WANG J, YAO J. "Production, purification and characterization of chitosanases produced by Gongronella sp. JG." Letters in Applied Microbiology. 2008, 46: 49-54.

13. Bradford MM. "A Rapid and Sensitive Method for the Quantitation of Microgram Quantities of Protein Utilizing the Principle of Protein-Dye Binding." Analytical Biochemistry. 1976, 72:248-254.

14. Chang WT, Chen YC, Jao CL. "Antifungal activity and enhancement of plant growth by Bacillus cereus grown on shellfish chitin wastes." Bioresource Technology. 2007, 98:1224-1230. 